\title{
Endometrial Intraepithelial Neoplasia
}

National Cancer Institute

\section{Source}

National Cancer Institute. Endometrial Intraepithelia/ Neoplasia. NCI Thesaurus. Code C27789.

A premalignant neoplastic process that affects the endometrial epithelium and glands. It is characterized by architectural glandular alterations and cytological abnormalities in the epithelial cells. The lesion exceeds $1 \mathrm{~mm}$ in maximum linear dimension. 